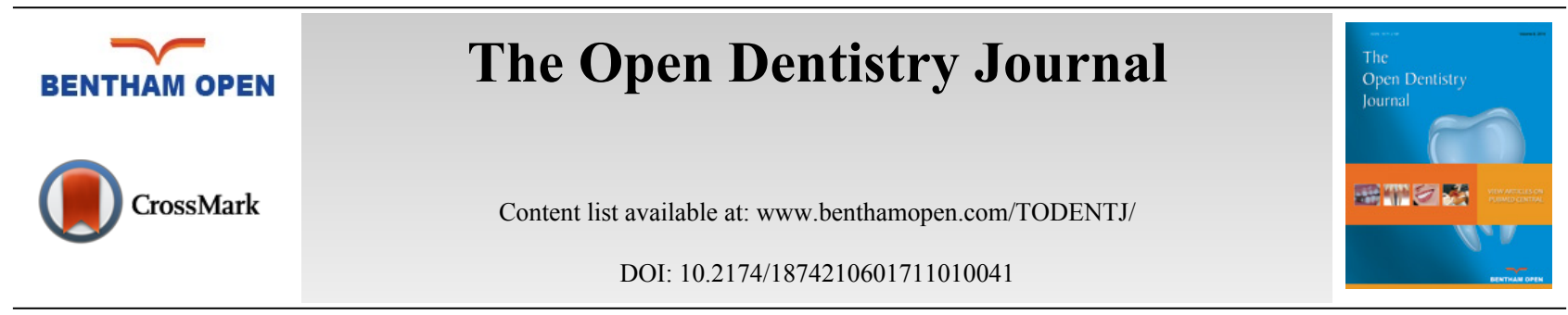

REVIEW ARTICLE

\title{
Social and Psychological Aspects of Dental Trauma, Behavior Management of Young Patients Who have Suffered Dental Trauma
}

\author{
Aristidis Arhakis ${ }^{*}$, Eirini Athanasiadou and Christina Vlachou \\ School of Dentistry, Aristotle University of Thessaloniki, Thessaloniki, Greece
}

Received: October 14, 2016

Revised: December 21, 2016

Accepted: January 03, 2017

\begin{abstract}
:
Introduction:

Injuries concerning the skull, the mouth and thus potentially involving the mouth and teeth are characterized as major public health problems due to their high prevalence and very serious functional and aesthetic consequences. Pain, aesthetic and functional problems arising from dental trauma significantly disrupt normal function, and impact, often dramatically, on young patients' quality of life.
\end{abstract}

\section{Procedure:}

With regards to the behavior management approach to a child who has suffered a dental trauma, dentist's first step is to be to reassure child and parents. They should feel that the emergency is being properly treated on the part of the dentist and feel safe. The dentist should offer psychological support to child and parents and focus on alleviating any possible pain the child may feel. But, before that, a good level of communication with the child should be established.

\section{Conclusion:}

This can be achieved through the tell-show-do technique, a presentation of the special session's structure, the positive reinforcement method, the attention distraction method and exploiting the child's imagination. The detailed description of the treatment to be followed is crucial for reducing the child's level of stress, as well as that of the parents. Immediately after the completion of treatment, dentist should give listening time to the parents for any queries and include the child who probably wants to share their experience.

Keywords: Dental trauma, Social/psychological aspects, Behavior management, Orofacial function, Occlusion and aesthetics, Oral Impact on Daily Performances (OIDP).

\section{INTRODUCTION}

Dental trauma is a painful experience that can impair orofacial function, negatively affecting growth, occlusion and aesthetics. At the same time, it has a significant impact, on an emotional and psychological level, distracting from the quality of life of young children and their parents [1].

A severe dental trauma, unlike a chronic condition, causes immediate and unexpected pain. Apart from the obvious economic cost, it can initiate a series of socio-economic consequences affecting the quality of life and possibly lead to the absence from school or work, sleep disturbances and changes in the daily schedule. Furthermore, children may experience stress from unhelpful behavior by their peers and inability to participate in school activities such as sports and music [2]. High-risk periods for dental trauma are childhood and adolescence, with about $80 \%$ of cases occurring in people under 20 years old. During this sensitive period of development, serious problems can occur in the management

* Address correspondence to this author at the School of Dentistry, Aristotle University of Thessaloniki, Thessaloniki, Greece; Tel: 0030-2310253553; Fax: 0030-2310999613; E-mail: oaristidis@gmail.com 
of dental trauma. Initially, patient compliance and cooperation are issues of primary concern for the dentist, while the importance of family involvement is particularly critical from the first moments after the injury. Subsequently, longterm monitoring is necessary, particularly in patients with a developing dentition. The psychological and social impact of dental trauma is generally recognized as having consequences that may affect social contact, emotional balance and well-being of the child [3].

In this literature review we will consider the possible social and psychological consequences of dental trauma in children, based on past studies, while simultaneously indicating the various behavior management techniques for approaching such emergencies in children and adolescents.

\section{SOCIAL AND PSYCHOLOGICAL CONSEQUENCES OF DENTAL TRAUMA IN CHILDREN}

Studies have shown that the appearance of the anterior teeth has important psychological and social impacts for the child. Consequently, the various injuries in the anterior tooth area can constitute significant emotional and social burdens for both the child and their family [4].

A study by Cortes et al. in 2002 involved 68 children 12-14 years old with unrestored enamel/dentine trauma and 136 children without a history of dental trauma. Using the Oral Impact on Daily Performances (OIDP) questionnaire the study concluded that children who had suffered a fracture in an anterior tooth reported being less satisfied from their food, maintained a negative attitude to tooth brushing, and felt less comfortable about smiling, laughing or showing their teeth, when socializing with people [5].

Giannetti, in 2007, observed frequent impacts on oral health, in patients who had undergone unsuccessful transplanting, after an avulsion trauma [6]. In their research, Ramos et al. (2007), studied the potential impact of the restoration of enamel/dentine fractures in children's daily lives, in a city of Brazil. The sample in this study comprised of 40 adolescents, aged 11 to 17 years, with enamel/dentine fractures, which had been restored up to six months earlier. The control group consisted of 160 children of the same age and similar socioeconomic status without a history of trauma. The index used was the Impact on Daily Performances (OIDP). The activities that appeared to be compromised in children with a history of trauma were: showing their teeth, chewing, speaking and, finally, brushing [7].

A few years later, in 2013, another study was performed in a city of Brazil. This time, the index used was the "Oral Health-Related Quality of Life" (OHRQoL) and in particular a questionnaire on the perceptions of children 11 to 14 years old, $\left(\mathrm{CPQ}_{11-14}\right)$, a form that considers 16 points. One thousand five hundred and twenty-eight $(1,528)$ twelve-yearold children were examined, with the existence of trauma in the permanent incisors being recorded together with socioeconomic status. In relation to questions concerning functional limitations, the group that had a trauma scored higher than the group that had never experienced dental trauma. No other area of the questionnaire was found to be associated with dental trauma [8].

In 2011, another study was conducted by Porritt et al., involving 244 children who visited a dental clinic in the United Kingdom for treatment of injured permanent incisors. In this study, apart from various clinical parameters (trauma severity, waiting time until treatment, required number of visits, etc.), psychosocial parameters were also considered, both initially and after six months. These parameters were measured on children with Oral Health-Related Quality of Life (OHRQoL) and Health-Related Quality of Life (HRQoL). Eventually, 108 children were involved in this research, of which only 70 participated in the six-monthly review. The results showed functional limitations and constrained school activities. The only clinical parameter that appeared to be statistically significantly different was the gender, with girls reporting more and greater extent of effects. Two thirds of the children reported minor effects still remaining at six months [9].

At the same time, in Tirana, Albania, the impact of untreated dental trauma on the quality of life of people 16-19 years old was studied. Ninety-five (95) people were selected from public schools, with untreated dental trauma constituted the subjects, while 190 people with no history of trauma comprised of the control group. The index Oral Impact on Daily Performances (OIDP) was used in this study, according to which an impact was recorded in $88.4 \%$ of trauma cases and in 58.9\% of the control group. The predominant impact, according to the index, related to "smile and showing the teeth without embarrassment" with the trauma group registering a significantly higher negative score [10].

Another recent study by Viera-Angrade et al., conducted in Brazil in 2015, studied the impacts of dental trauma on preschool children. Three hundred and thirty-five (335) children 3-5 years old from private kindergartens evaluated their quality of life after trauma, using the Early Childhood Oral Health Impact Scale (ECOHIS) index. In these age groups, apart from some references to pain and difficulty in chewing, no statistically significant difference was found in 
quality of life between children with and without dental trauma [11].

However, a study by Aldrigui et al. in 2011 concluded that complex dental traumatic injuries have a negative impact on Oral Health and quality of life of preschool children and their parents. Therefore, it is necessary for children to have access to dental care services when they suffer dental injuries in order to avoid other negative effects on their quality of life [12].

In a similar study carried out by Abando et al. (2014) in São Paulo, the researchers studied whether the child's quality of life is downgraded - according to reports of the children and their parents - due to decay and dental trauma. Three hundred thirty-five (335) children aged 5-6 years filled in the Scale of Oral Health Outcomes for 5-year-old children (SOHO-5). The results showed that decay, but not dental trauma, was associated with lower levels of the index both by children's and parents' reports [13].

It is also interesting how a dental trauma is perceived by others. In a recent study of Awooda \& Ali (2015) from Sudan, the way in which children see their peers with visible trauma to the incisors was investigated. Children aged 10-11 and 14-15 years were asked to rate 4 photos of children with or without trauma to the incisors. Children with trauma were judged more negatively than children without any trauma by both age groups [14]. A respective study was also previously conducted in Great Britain by Rodd et al. (2010) with younger children judging the photos of children with a trauma to anterior teeth more negatively compared to the older age group. This difference was attributed to the greater emotional maturity of adolescents [15].

Finally, one more study, conducted in Canada by Fakhruddin et al. (2008), used the Child Perception Questionnaires $\left(\mathrm{CPQ}_{11-14}\right)$ index to assess the social impact of trauma on quality of life of 2,422 children, aged 12-14 years. The sample was divided into 3 groups: 1) children without dental trauma, 2) children with dental trauma that remained untreated, and 3) children with dental trauma that had been restored. Children with untreated trauma reported statistically significantly greater difficulty in chewing, social contacts and smiling compared to uninjured children. Children who had been injured but treated reported only the difficulties in chewing, without any effect on their psychological state [16]. The impact of injury to the upper central incisors on the social welfare of children was greater than the functional and psychological well-being in children 12-14 years old. Children with untreated dental trauma showed greater negative social impact on their daily life than those without injury or injury for which medical help had been sought. This confirms the findings of Cortes et al. (2002) reporting that aesthetics rather than functional limitation was a serious issue for children with tooth fractures [5]. As expected, children with untreated dental traumas also had limitations associated with chewing. The study of Fakhruddin et al. (2008) shows that children with dental trauma, treated promptly and with good aesthetic results show no negative social behavior in their everyday life. The appearance of the teeth and dental problems associated with dental injuries may affect the psychological and social well-being of children and downgrade their quality of life. Especially, dental trauma left untreated is more likely to have an impact on children's everyday life than a treated one [16].

\section{BEHAVIOR MANAGEMENT OF YOUNG PATIENTS WHO HAVE SUFFERED A DENTAL TRAUMA}

Regarding the recommended approach of children admitted for surgery with a trauma, it is crucial for the dentist to understand the special psychological state of both the child and their parents. So, as a first step, apart from the selection of the appropriate trauma treatment, the dentist should try to reassure the child and their parents, and alleviate their mental stress. The practitioner's knowledge, experience and ability to intervene immediately and effectively relieve the young patient's distress play a key role in this effort [17].

At this point, it is very important to mention, in order to approach a patient ideally, the dentist - therapist should put themselves in the child's position, and attempt to view the trauma through their patient's eyes. According to a study of Vlok et al. in 2011, what the patient sees and what the dentist faces as well as how patients perceive their situation according to their age group were found to be quite different. The difference between 6-10 years and 18-24 years groups, in terms of what they perceived as more painful, was statistically significant. The perception of young patients seemed to be affected by the presence or absence of blood and they considered avulsion the most painful trauma, while they appeared to be not particularly concerned about the loss of an anterior tooth. The older ones focused on things relating to the tooth and considered crown fracture with pulp involvement as the most painful. As to the dentists, they considered crown fracture more difficult to treat for both age groups [18].

It is also important to describe the context that a dental trauma occurs. First, the trauma itself is a painful experience for the child. Moreover, as an incident it is classified in the category of an emergency. A waiting room packed with 
urgent appointments never creates a pleasant atmosphere because there is always crowding and it is dominated by feelings of anxiety. As for the therapy itself, the immediate treatment of dental trauma is often a painful and frightening process for the child. Presence of pain and absence of properly informing both patient and parents could complicate the therapy process more. Due to the often problematic initial treatment of dental trauma, very often there is anxiety on the part of the parents about complications arising at a later time, with the possibility of financial burden on the family being an additional consideration.

Therefore, the overriding need, when the emergency incident arrives at the dentist's office, is the reduction or even elimination of pain as quickly as possible. The prevention and control of pain during any dental treatment is one of the most important parameters in order to be provided integrated, qualitative dental care to patients. This is especially important as far as children are concerned. The achievement of a high degree of cooperation, the development of confidence, the prevention of dental phobia creation and the establishment of a positive perception of dental practice are decisively associated with minimizing discomfort and complete absence of pain in the dental office [19]. Many studies have concluded that the main causes of dental fear and avoidance of dental treatment are painful or negative dental experiences [20,21].

The first step that dentists should make in approaching the child is to explain them that the dentist is there to help and reassure them. In cases where the only eventual solution is to extract the tooth, this information should be omitted at this stage. The "tell-show-do" technique introduces the child step by step in the world of dental (or other) experience, thus making the unknown gradually known. It was described by Addelston (1954) more than half a century ago and can be used without any contraindication. It is used for children with or without previous dental experience assisted by other techniques such as mainly positive reinforcement (reward) and control provision at each stage of compliance with those requested. Using the "tell-show-do" technique, the dentist can explain to the child what is going to happen and what exactly they are going to feel during treatment. The time devoted to this part should never be considered a "waste of time", because, in fact, it is an investment. The clinician builds a trusting relationship with the child, a basis necessary for any treatment to follow. Communication with the child must be sincere and meet the mental maturity level of the child. It is particularly important for children to feel that they participate in their treatment process, giving them the right of choice (e.g. what superficial anesthetic taste to use) [22, 23].

Because there is the likelihood, at some point, of the child feeling pain, either due to neglect by the dentist or because it is inevitable, it is necessary for the child to have some control, e.g. by raising his/her hand. This allows the dentist to stop the painful stimulus without interrupting the process, correct the cause of pain and continue normally. Thus, the child maintains its dignity and keeps it intact throughout a process often difficult for their age [23, 24].

Acceptance (positive reinforcement) increases the likelihood of repeat while rejection (negative reinforcement) theoretically reduces it. Positive reinforcement or reward is necessary for the dentist to ensure the young patient's desired behavior. This technique, therefore, is the deliberate use of rewards to encourage repeat of the desired behavior. These can be: verbal by the dentist or non-verbal such as facial expression, tone of voice or a touch on the shoulder, as well as reward with a small gift at the end of the session. It should be noted that by raising a hand at a painful stimulus the child uses his intelligence to control his anxiety, along with the cessation of the stimulus. Thus, we have an excellent opportunity to praise the child, because they achieved something difficult by not losing composure. Our praise raises the self-esteem and the child feels the love; and the child or adult who believes that he is capable and being loved has the necessary skills to function successfully in society [23]. Health professionals should identify and manage their emotions in relation to the patient. Even if therapists are affected by what they see, they should learn to manage the situation so that nothing is noticed by the parents and/or the child. Apart from verbal communication, body language sometimes also betrays emotions, easily understood by young children. The eye-contact and the tone of voice are elements that allow communication even with a very young child and they, in turn, may respond with a smile, crying, interest, escape movements, etc. As the young patients grow, words become increasingly more powerful in patientdentist communication [24].

The attention distraction technique attempts to direct the child's thought and attention, away from something they consider unpleasant. Various techniques, such as narration of a story or fairy a tale, reference to extracurricular activities of the child, visual or auditory projections (animation, music, etc.) could be used. Stimulation of imagination and discussion on issues of interest (computer games, TV, etc.), are considered a better attention distraction than talking about the weather or the club the child supports. In a related study, the use of talking about non-dental issues was not particularly effective in reducing fear, thus not providing documentation of the technique. Attention distraction should not be used at the expense of keeping the child informed. Holding a mirror gives information to the child, while 
simultaneously distracting their attention. The child is so often absorbed by the image that he may think that all these things are happening with someone else [23, 24].

The presence of parents is very important for the psychological support of the child. If this is not possible, another adult must take this role. Parents should actively participate and be informed about anything regarding the condition of their child. Specifically, only when parents feel reassured, concerning the dental trauma treatment, are able to support and comfort their child. This element applies to both children and young teenagers. The behavior of the whole dental office personnel is also important. Both the dentist and other personnel must show willingness to listen and calm the child and parents even in this highly stressful situation, providing a reassuring sense of professional knowledge and competence. The patient's reception environment must be specially designed to exude a sense of calmness and intimacy and include elements capable of distracting child's attention. That is, in no case a "sterile" hospital environment is desirable [23].

Finally, in some cases where the child stubbornly refuses cooperation or is hysterical, many people believe that exercising physical restriction to restore communication is justified. A technique by which this refusal cycle can immediately be interrupted is called "hand over mouth" and is described by some pediatric dentists of North American origin $[25,26]$. However, it is considered a highly interventional technique. Instead of the "hand over mouth" technique aimed at the beginning of communication with the child with stubborn temperament, the temporary deprival of the parent's presence and their reappearance as a positive enhancer of the improved behavior can also be used [27, 28]. A prerequisite for the application of this technique is the acceptance by the dentist of the presence of a parent when working. The instinct of non-separation from the parent for survival is inherent, while the dependency on the parent is maintained at least for the first decade of childhood [29]. Children with negative behavior in the dental office during the first session seek the parent's presence as it enhances the feeling of safety. Young children know that their parent will approach them when they begin to cry in the same way when they are in danger. With this in mind, they often exploit parental presence to avoid dental examination and treatment, pushed by their fears [30]. In these cases, a short but comprehensive simultaneous briefing of the parent and child may take place, followed by consent of the parent. The message to be given is that a parent is welcome, but as the dentist has an obligation to stop when the child raises a hand, the same way the child is required to raise a hand only when annoyed and not crying or shouting. In the latter case, the dentist informs, in a voice that shows primarily care and stability as well, that they are going to ask the parent to go out because children "grumble more when their parents are present" and he/she will return immediately after the young patient's behavior improved. In cases where unacceptable behavior continues, it is not helpful to extend the stay. The parent goes out and stays out of the child's sight. If the dentist's office has the necessary room, some parents prefer to watch the unseen manipulations to achieve communication and cooperation. To the child who promises "get my mom and I will stop" the dentist says: "I want to make sure that you have stopped and then I will call her. I don't think that you'll be annoyed by anything but, if you wish, you can stop me by raising your hand". If crying continues in the form of hysteria, the dentist tries to ask if the child wants his mother, i.e. to start communication. On hearing an affirmative answer the attempts should be made to continuously pass the message that if the child wants the mother's presence, then he should help in order to achieve this. That is, against the child's instinct to bring the mother by crying, they are guided to learn that she will come in the requested manner [28].

\section{CONCLUSION}

Regarding the psychological approach to a child presenting at the dentist's office with a dental trauma, it is crucial for the dentist to approach the young patient with understanding, tenderness and love and to be able to manoeuvre by compromising on some less important issues. With this attitude, the dentist shows respect for the child's feelings and helps him in his effort to maintain composure. Psychological approach techniques, such as the "tell-show-do" technique, control provision, positive reinforcement (reward), attention distraction, exit warning/parent exit, movement limitation - Immobilization, should always be in the dentist's quiver. Each dentist can be effective with whichever approach suits them personally, if they are experts in the techniques required. The dentist can use this approach as long as it is within the official organizational guidelines, such as the International, the European or the American Academy of Pediatric Dentistry, and, of course, they have the consent of parents.

\section{CONFLICT OF INTEREST}

The authors confirm that this article content has no conflict of interest. 


\title{
ACKNOWLEDGEMENTS
}

\author{
Declared none.
}

\section{REFERENCES}

[1] Diab M, elBadrawy HE. Intrusion injuries of primary incisors. Part I: Review and management. Quintessence Int 2000; 31(5): 327-34. [PMID: 11203943]

[2] Wong FS, Kolokotsa K. The cost of treating children and adolescents with injuries to their permanent incisors at a dental hospital in the United Kingdom. Dent Traumatol 2004; 20(6): 327-33.

[http://dx.doi.org/10.1111/j.1600-9657.2004.00263.x] [PMID: 15522054]

[3] Lee JY, Divaris K. Hidden consequences of dental trauma: the social and psychological effects. Pediatr Dent 2009; 31(2): 96-101. [PMID: 19455926]

[4] Helm S, Kreiborg S, Solow B. Psychosocial implications of malocclusion: a 15-year follow-up study in 30-year-old Danes. Am J Orthod 1985; 87(2): 110-8. [http://dx.doi.org/10.1016/0002-9416(85)90020-X] [PMID: 3855604]

[5] Cortes MI, Marcenes W, Sheiham A. Impact of traumatic injuries to the permanent teeth on the oral health-related quality of life in 1214-yearold children. Community Dent Oral Epidemiol 2002; 30(3): 193-8. [http://dx.doi.org/10.1034/j.1600-0528.2002.300305.x] [PMID: 12000342]

[6] Giannetti L, Murri A, Vecci F, Gatto R. Dental avulsion: therapeutic protocols and oral health-related quality of life. Eur J Paediatr Dent 2007; 8(2): 69-75. [PMID: 17571930]

[7] Ramos-Jorge ML, Bosco VL, Peres MA, Nunes AC. The impact of treatment of dental trauma on the quality of life of adolescents - a casecontrol study in southern Brazil. Dent Traumatol 2007; 23(2): 114-9. [http://dx.doi.org/10.1111/j.1600-9657.2005.00409.x] [PMID: 17367459]

[8] Damé-Teixeira N, Alves LS, Ardenghi TM, Susin C, Maltz M. Traumatic dental injury with treatment needs negatively affects the quality of life of Brazilian schoolchildren. Int J Paediatr Dent 2013; 23(4): 266-73. [http://dx.doi.org/10.1111/ipd.12002] [PMID: 23016995]

[9] Porritt JM, Rodd HD, Ruth Baker S. Quality of life impacts following childhood dento-alveolar trauma. Dent Traumatol 2011 ; $27(1)$ : 2-9. [http://dx.doi.org/10.1111/j.1600-9657.2010.00943.x] [PMID: 21129159]

[10] Thelen DS, Trovik TA, Bårdsen A. Impact of traumatic dental injuries with unmet treatment need on daily life among Albanian adolescents: a case-control study. Dent Traumatol 2011; 27(2): 88-94. [http://dx.doi.org/10.1111/j.1600-9657.2010.00957.x] [PMID: 21281440]

[11] Vieira-Andrade RG, Siqueira MB, Gomes GB, et al. Impact of traumatic dental injury on the quality of life of young children: a case-control study. Int Dent J 2015; 65(5): 261-8. [http://dx.doi.org/10.1111/idj.12182] [PMID: 26311004]

[12] Aldrigui JM, Abanto J, Carvalho TS, et al. Impact of traumatic dental injuries and malocclusions on quality of life of young children. Health Qual Life Outcomes 2011; 9: 78. [http://dx.doi.org/10.1186/1477-7525-9-78] [PMID: 21943368]

[13] Abanto J, Tsakos G, Paiva SM, Carvalho TS, Raggio DP, Bönecker M. Impact of dental caries and trauma on quality of life among 5- to 6year-old children: perceptions of parents and children. Community Dent Oral Epidemiol 2014; 42(5): 385-94. [http://dx.doi.org/10.1111/cdoe.12099] [PMID: 24460685]

[14] Awooda EM, Ali YA. Social judgments made by children (1015 year old) in relation to visible incisors trauma: School-based cross-sectional study in Khartoum state, Sudan. J Int Soc Prev Community Dent 2015; 5(5): 425-31. [http://dx.doi.org/10.4103/2231-0762.165931] [PMID: 26539397]

[15] Rodd HD, Barker C, Baker SR, Marshman Z, Robinson PG. Social judgements made by children in relation to visible incisor trauma. Dent Traumatol 2010; 26(1): 2-8. [http://dx.doi.org/10.1111/j.1600-9657.2009.00849.x] [PMID: 20089056]

[16] Fakhruddin KS, Lawrence HP, Kenny DJ, Locker D. Impact of treated and untreated dental injuries on the quality of life of Ontario school children. Dent Traumatol 2008; 24(3): 309-13. [http://dx.doi.org/10.1111/j.1600-9657.2007.00547.x] [PMID: 18410390]

[17] Jacobsen I, Andreasen JO. Pediatric Dentistry A clinical approach. $4^{\text {th }}$ ed. Oxford: Blackwell 2009; pp. $264-97$.

[18] Vlok JL, Worthington EM, Hindson JA, Davidson LE, Thomson WM, Drummond BK. Young peoples perceptions of photographs of dental trauma. Dent Traumatol 2011; 27(2): 109-12. [http://dx.doi.org/10.1111/j.1600-9657.2010.00969.x] [PMID: 21385313]

[19] Wilson S, Dilley DC, Vann WF. Pediatric dentistry Infancy through adolescence. $5^{\text {th }}$ ed. St Louis: Elsevier Saunders 2005 ; pp. 108-29. Chapter 7

[20] Arapostathis KN, Coolidge T, Emmanouil D, Kotsanos N. Reliability and validity of the Greek version of the Childrens Fear Survey 
Schedule-Dental Subscale. Int J Paediatr Dent 2008; 18(5): 374-9.

[http://dx.doi.org/10.1111/j.1365-263X.2007.00894.x] [PMID: 18284471]

[21] Saravia ME, Bush JP. The needleless syringe: efficacy of anesthesia and patient preference in child dental patients. J Clin Pediatr Dent 1991; 15(2): 109-12. [PMID: 1931745]

[22] Addelston HK. Child patient training forth. Rev Chicago Dent Soc 1959; 38(7-9): 27-9.

[23] Kotsanos N. Paediatric Dentistry-Evidence based total care. Fylatos Publishing Thessaloniki 2015; pp. 77-97.

[24] Weinstein P, Getz T, Ratener P, Domoto P. The effect of dentists behaviors on fear-related behaviors in children. J Am Dent Assoc 1982; 104(1): 32-8. [http://dx.doi.org/10.14219/jada.archive.1982.0117] [PMID: 6948027]

[25] Craig W. Hand over mouth technique. ASDC J Dent Child 1971; 38(6): 387-9. [PMID: 4256168]

[26] Levitas TC. HOME-hand over mouth exercise. ASDC J Dent Child 1974; 41(3): 178-82. [PMID: 4275104]

[27] Rayman MS. Parent observation. CDA J 1987; 15(8): 20-4. [PMID: 3478144]

[28] Kotsanos N, Arhakis A, Coolidge T. Parental presence versus absence in the dental operatory: a technique to manage the uncooperative child dental patient. Eur J Paediatr Dent 2005; 6(3): 144-8. [PMID: 16216095]

[29] Sonis AL, Ureles SD. Workshop on parenting methods to minimize disruptive behavior. Pediatr Dent 1999; 21(7): 469-70 [PMID: 10681245]

[30] Frankl S, Shiere F, Fogels H. Should the Parent remain with the child in the dental operatory? ASDC J Dent Child 1962; $29:$ 150-63.

(C) Arhakis et al.; Licensee Bentham Open

This is an open access article licensed under the terms of the Creative Commons Attribution-Non-Commercial 4.0 International Public License (CC BY-NC 4.0) (https://creativecommons.org/licenses/by-nc/4.0/legalcode), which permits unrestricted, non-commercial use, distribution and reproduction in any medium, provided the work is properly cited. 